\title{
Assessment of Dominant Trends in Housing Construction Market in Russia
}

\author{
Tatiana Ovsiannikova, Olga Rabtsevich and Irina Yugova*
}

Department of real estate expertise and management, Federal State budgetary educational institution of higher education "Tomsk State University of Architecture and Building", TSUAB, Solyanaya sq.

2, Tomsk, 634003, Russia.

\begin{abstract}
The article is devoted to the research and assessment of dominant trends in the development of the housing construction market in Russia. The relevance of the study is determined by the role of the housing construction market as a driver of economic development of territories. The purpose of the study is to assess the current trends in the development of housing construction. The conducted analysis showed that the condition and dominant trends of the housing construction market generally corresponded to the negative macroeconomic situation in 2020. The factors that caused the negative trends in the development of the housing construction market are identified and their consequences are assessed. The authors believe that timely identification and assessment of dominant trends in the housing construction market allow predicting possible directions of its development, which in turn allow specifying directions of state regulation of the housing sector necessary to maintain stability of the industry and its balanced development.
\end{abstract}

\section{Introduction}

The role of housing investment in the economy of any state is extremely crucial. It is determined by two main factors:

1. Housing is a basic commodity for a person and it belongs to the so-called merit goods: it is able to provide for basic human needs, but at the same its benefits to society are incomparably greater (Stanly Fischer, 2017) [1]. Advanced housing security of population ensures social and political stability, contributes to the formation of high-quality human capital, reduces criminal activity and ultimately ensures well-being and prosperity of the state.

2. Housing investments have a significant multiplier effect, attracting investments in

* Corresponding author: saykova86@mail.ru 
related sectors of economy and contributing to significant economic growth (Harold Katsura, 1984) [2], (Leonid Poliakov, 2000) [3], Tatiana Ovsiannikova, Olga Rabtsevich, Irina Yugova, 2017) [4] and others.

Therefore, the housing construction market in all countries is one of the most regulated and supported by the state. However, another reason for the government's attention to the housing development is a close link between housing markets and global financial crises.

The link between existing housing finance mechanisms and global financial crises has been pointed out by many researchers (Eugenio Cerutti, Jihad Dagher, and Giovanni Dell'Ariccia, 2015) [5], (Colin Jones, 2016) [6], (Stanley Fischer, 2017) [1]. A study by experts of International Monetary Fund (E. Cerutti, J. Dagher, and G. Dell'Ariccia, 2015) is of interest. They investigated the link between the real estate boom and the risks of global financial crises, and proved that global financial crisis highlighted the risks associated with real-estate booms. The authors investigated 85 episodes of accidental booms in real estate markets in 50 countries and came to a conclusion that household-credit booms and houseprice booms tend to occur together. Regression analysis suggests that household-credit booms are good predictors of real-estate booms. It bears repeating that the world economic crisis of 2008-2009 was triggered by the mortgage boom and the boom in the real estate market in the United States.

One of the tasks of the state economic policy including housing policy is to identify the signs of financial crises and develop measures to eliminate factors of economic instability. Therefore, the study and evaluation of dominant trends in housing development might allow performing analysis of evolving industry dynamics and assumptions underlying their conditions and factors, as well as identifying constraints and potential opportunities to enhance economic activity in the housing market. Timely identification of negative trends in the development of the market allows the government to adjust the state economic policy and avoid a deep crisis.

In this regard, the aim of this research is to identify dominant trends in the development of the housing construction market, which are formed under the influence of factors of the external and internal environment of the market. The assessment of dominant trends in the housing construction market in Russia will allow predicting the possible directions of its development, which, in turn, will allow further determining the directions of state regulation in the housing sector necessary to maintain stability of the industry.

This article presents the results of the analysis of the main indicators of the development of housing construction. Based on this analysis, the dominant trends in the dynamics of housing supply and demand in the housing construction market, in the formation of a competitive environment, in the development of the mortgage lending system and changes in prices in the housing market are identified.

\section{Methods}

The research is based on general scientific methods involving utilization of logical, systematic, structural and complex analysis to achieve the research aims, as well as statistical analysis methods - generalization, data grouping and time series analysis. Information basis of the research was the statistical data of Rosstat (Federal State Statistics Service of Russia), Unified Information System for Development of Housing Construction "Nash.Dom.RF", as 
well as data from the Central Bank of the Russian Federation. Development of trends and forecasting of indicators for the development of housing construction is carried out using factor analysis.

The research is based on methodological principles of reliability, objectivity and integrity of information and validity of judgments and conclusions.

\section{Results}

The first dominant trend in the housing investment market is the reduction in the supply of housing under construction. Analysis of the dynamics of housing construction over the past 10 years has shown that while housing construction increased by $46.1 \%$ over the period of 2010-2015, its volume decreased by $5.5 \%$ in 2015-2020 (Fig. 1).

The reduction in the supply of new housing was caused by the following factors:

- previously observed negative trends in the development of housing construction caused by the crisis of 2015-2016;

- transition of housing construction industry to a new financing mechanism, that is project financing;

- impact of the COVID-19 pandemic-related economic crisis on the development of the housing investment market in 2020 .

There had been an increase in the supply of housing in the housing investment market until 2015, due to the influx of investment resources of the population, whose purchasing ability increased in 2013-2015 because of general economic recovery. The key features of shared-equity construction (reduced administrative barriers to entry into the industry for medium and small construction organizations; absence of additional factors of construction projects' cost increase and availability of public funds) made it possible to achieve the volume of housing construction at the level of $85.3 \mathrm{mln}$. sq. $\mathrm{m}$. of housing per year by 2015 , including the $50.1 \mathrm{mln}$. sq. m. of developers' housing commissioning (Fig. 1). But these figures remained the highest as deterioration of the foreign economic situation in 2015-2016 led to a considerable reduction in household incomes and shortage of financial resources of developers, which caused a drop to $75.7 \mathrm{mln}$. sq. m. in housing construction in 2018 .

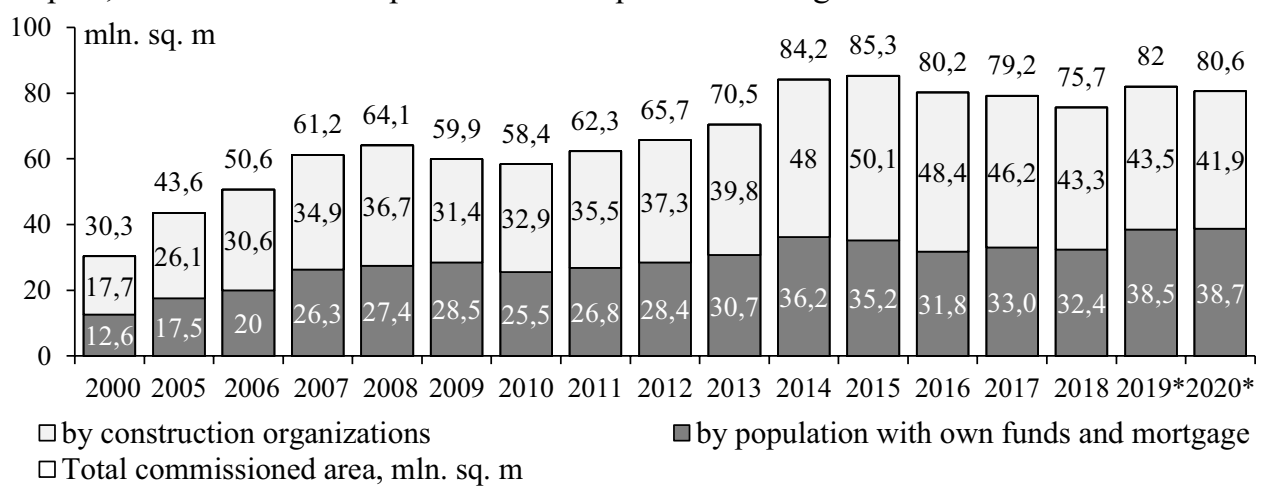

Fig. 1. Dynamics of commissioning of residential houses in Russia (commissioned area of dwellings, mln. sq. m, drawn according to Rosstat data [7]). 
One of the most significant changes that have occurred in the field of housing construction in Russia in recent years is the introduction of a new project financing mechanism for Russian developers and the transition to escrow accounts.

The housing construction financing in Russia was predominantly carried out at the expense of housing equity holders since 2004. The construction equity funding mechanism supported the supply and demand in the housing market for almost fifteen years, because it simultaneously gave an opportunity to population to purchase housing on deferred payment terms, and the opportunity to obtain an interest-free financing of the investment process at the earliest stages of construction to developers. Utilization of this mechanism, on the one hand, facilitated the development of construction complex, but, on the other hand, led to the problem of "deceived equity holders", which was the result of insufficient security and stability of the system. Fluctuations in the economic environment caused by instability of external and internal economic and political situation led to bankruptcy of developers who did not have enough funds, and impossibility of completing construction on a great number of construction projects that had been commenced.

In 2019 the state initiated a change in the housing construction financing mechanism, which affected not only the change in the financing mechanism, but also strengthening of requirements to prepare project and title documentation for developers. It was assumed that the new mechanism would solve the problem of lack of financial resources during implementation of housing construction projects.

The transition to project financing of housing construction in 2018-2020 produced both negative and positive effect on development of the housing investment market. The positive impact of the industry's transition to project finance was reflected in increased sustainability of housing construction during the crisis caused by the COVID-19 pandemic.

The negative impact of the funding mechanism transition on housing construction dynamics manifested itself in reduction of the growth rate of housing construction in 20182020 as a result of necessity to adapt to new business conditions and exit of small construction organizations from the market due to stringent industry entry barriers (if in 2012-2015 the average growth rate of new housing was $8.2 \%$ (calculated according to [7]), the growth rate in 2018-2020 reduced to $0.6 \%$ ). As a result, $47.1 \mathrm{mln}$. sq. $\mathrm{m}$. of housing area were introduced using escrow accounts at the end of 2020 while only $26.7 \mathrm{mln}$. sq. m. at the beginning of 2020 [8]

Establishment of requirements for the size of the authorized capital of construction organizations also led to a decrease in the level of competition in the housing investment market, which resulted in strengthening of the second dominant trend in the development of the housing investment market that is decrease in market competition. There was a revival of oligopolization of the housing construction market thus the growth of the HerfindahlHirschman index characterizing the level of market concentration observed in $60 \%$ of the Russian regions in 2020 (calculated according to [9, 10]).

Grouping of regions by the value of the Herfindahl-Hirschman index also confirms the growing concentration of producers in the housing investment market. As can be seen from the graph in Figure 2, the number of regions with an average level of competition decreased in 2020, however there was an increase in regions with a low level of competition. 


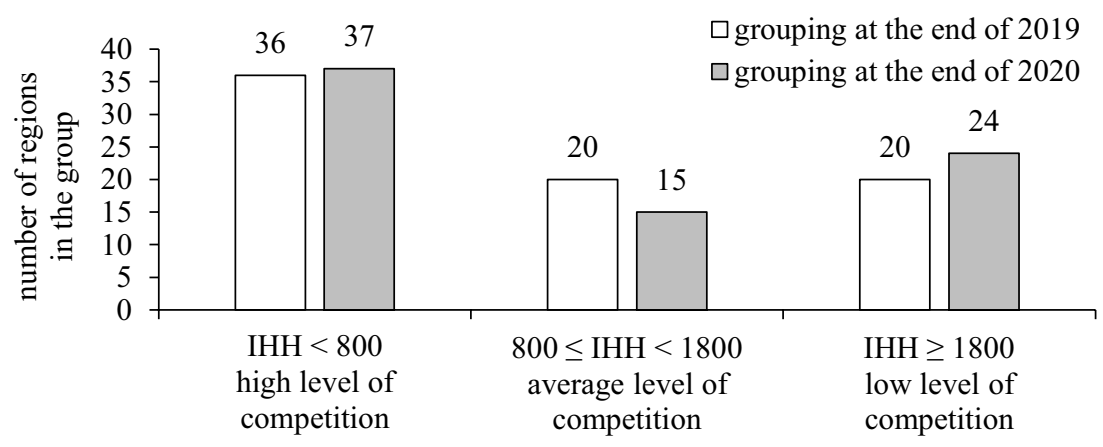

The groups of regions according to the value of the

Herfindahl-Hirschman index

Fig. 2. Grouping of Russian regions by the value of the Herfindahl-Hirschman index (calculated according to $[9,10])$.

The third dominant trend in the housing investment market is the growth in demand for new housing.

Despite adverse conditions for all participants of the housing investment market, the main positive trend in the development of the market in 2020 was the increase in demand for newly built housing. This happened under the influence of the following factors:

- inflation expectations due to the introduction of a new financing mechanism and the publicly discussed problem of the inevitable rise in housing prices due to the rising cost of financial resources for developers;

- devaluation of the national currency: potential buyers rushed to protect their depreciating savings by buying real estate;

- $\quad$ reduction in the profitability of financial assets (bank deposits) - investors, primarily non-institutional investors (the population), preferred real estate assets with slightly higher returns and significantly lower investment risks;

- introduction of the state program of preferential mortgages increasing the availability of mortgage loans provided an increase in the purchasing ability of the population in the residential real estate market.

Implementation of the preferential mortgage loan program in 2020 was the main mechanism of state support for housing construction during the economic crisis and determined the formation of the fourth dominant trend in the development of the housing investment market.

The fourth dominant trend in the housing investment market is an increase in the volume of mortgage housing credit. In 2020 the maximum number of mortgage loans in the entire history of mortgage in Russia was issued. The overall number of approved mortgages reached 1.7 million loans (Fig. 3).

The factor of increase in the volume of housing mortgage loans was the reduction of the mortgage rate for loans to purchase new housing to $6.5 \%$ per annum. Lower interest rates in the primary housing market also led to a slight reduction in lending rates in the secondary housing market. According to the Integrated housing development institution DOM.RF, the minimum mortgage rate at the end of 2020 in the primary housing market was $5.9 \%$ while in the secondary housing market $-8.1 \%$ [3]. 


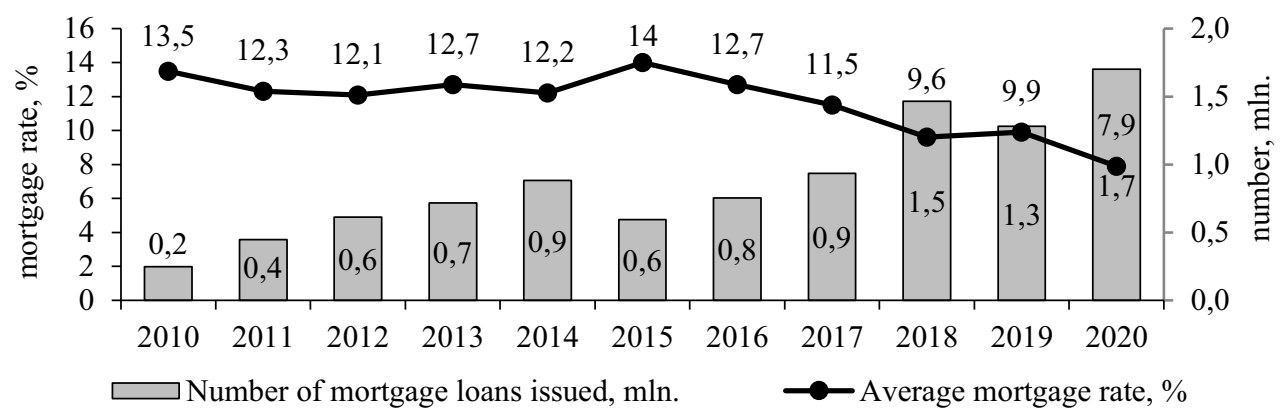

Fig. 3. Average mortgage rate and number of mortgage loans in Russia (drawn according to $[13,14])$.

Increased availability of mortgage loans in 2020 provoked increase in housing investment demand which in turn prevented a significant decrease in the volume of residential construction when socio-economic situation in the country became worse. But at the same time, laws of the market economy determined the response of supply to the growth of demand and led to emergence of the fifth dominant trend in the development of the housing investment market in Russia.

The fifth dominant trend in the housing investment market is the growth of housing prices. In 2020 there was the maximum increase in prices for new housing in Russia for the period of 2010-2020 compared to 2019. The prices increased by $12 \%$ and amounted to 79.0 thousand rubles per sq. m. of housing area (Fig. 4).

The factors that determined the fifth trend were:

- an increase in demand for new housing, which led to emergence of a certain supply shortage in the housing construction market and to an increase in housing prices: in the housing market in St. Petersburg, price growth in 2020 was from 13 to $15 \%$, in Moscow more than $16 \%$, in New Moscow - more than $27 \%$ [17]. This process almost outweighed social effects of the measures of state financial support of demand;

- reduction in the level of competition in the housing construction market and increase in monopolization of the industry.

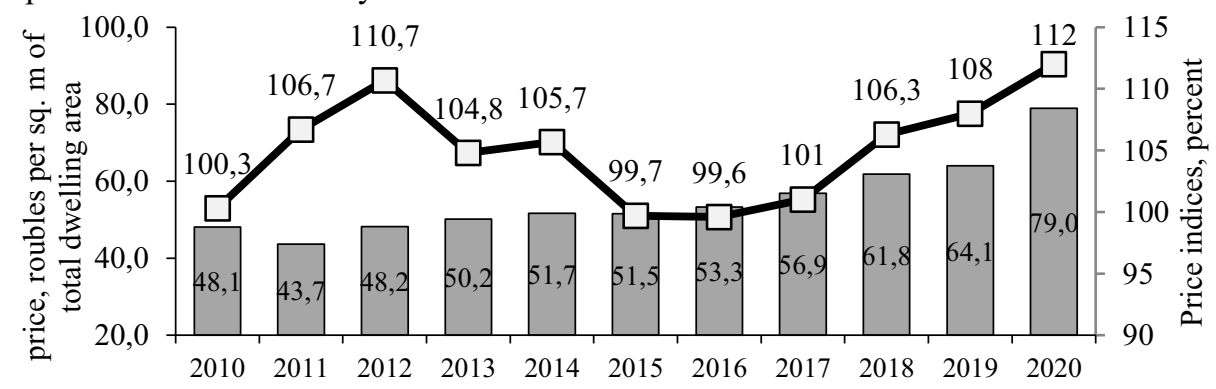

$\square$ Average annual market price, roubles per sq. $\mathrm{m}$ of total dwelling area

$-\square$ Price indices, end of year in percent of end of previous year

Fig. 4. Dynamics of the average annual prices and price indices for new housing in Russia (drawn according to $[15,16])$. 


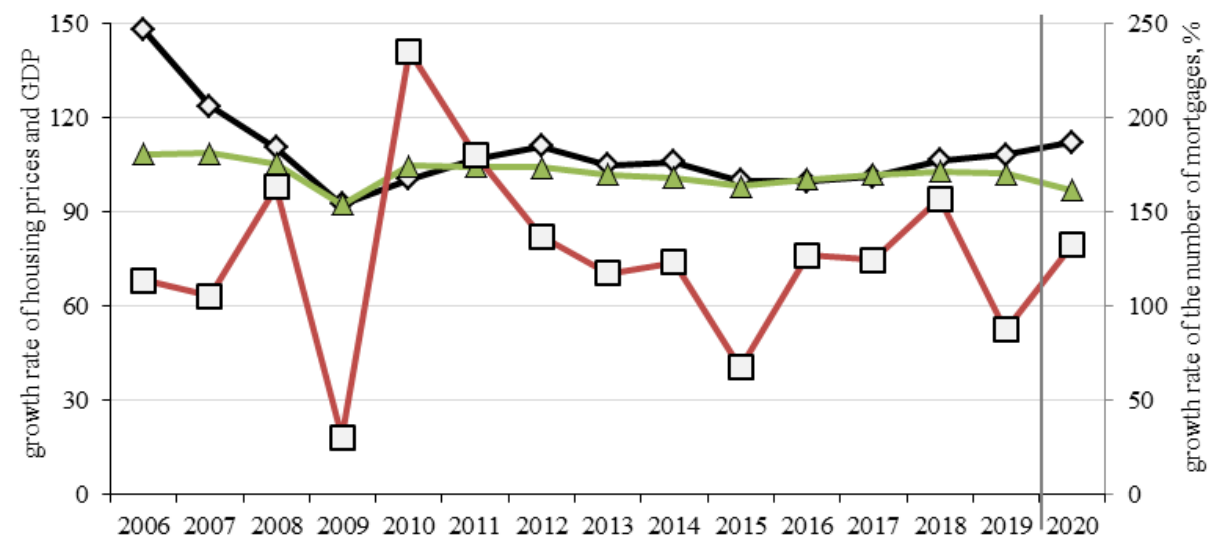

$\Longrightarrow$ Price indices in the primary housing market as a percentage of the previous year $\triangle$ GDP growth rate in comparable prices as a percentage of the previous year $-\square-$ growth rate of the number of mortgage loans as a percentage of the previous year

Fig. 5. Dynamics of number of mortgage loans, prices in the primary housing market and GDP (drawn according to $[13,14,16,19])$.

It is worth mentioning that the price dynamics in the housing investment market corresponds to the phenomenon of "asymmetric reaction" of prices to fluctuations in the exchange rate and the yield of financial assets, which is confirmed by a study of Bank of Russia experts: "in all regions, the weakening of the ruble leads to a statistically significant increase in prices, while the strengthening does not affect inflation" [18].

It goes without saying that dynamics of prices in the residential real estate market does not have such volatility as in the consumer goods market where the trends have a more longterm character characterized by a steady growth.

\section{Discussion}

The crisis has had a significant impact on the dynamics of the housing market. According to the monitoring of the Bank of Russia the capacities of construction enterprises in the first half of 2020 were employed at 65-66\% [11]. The market situation was also complicated by quarantine restrictions in the conditions of the COVID-19 pandemic: suspension of production, shortage of labour migrants, interruptions in construction resource import.

Utilization of developers' own funds and credit resources to finance construction made it possible to avoid risks of a shortage of funds among developers during the decrease in the rate of housing sales [12].

Despite that one of the dominant trends of the housing investment was the reduction in supply of new housing, improved sustainability and increasing demand for newly built apartments in 2020 allowed avoiding a significant drop in the amount of housing commissioning which only decreased by $1.7 \%$ compared to 2019 . 


\section{Conclusions}

The given analysis showed that the condition and dominant trends of the housing construction market in 2020 generally corresponded to the negative macroeconomic situation. However, the dominant trends that will determine parameters of housing construction in the future are the following:

1. The supply of new housing in the housing investment market decreased due to the following factors:

- introduction of escrow accounts;

- $\quad$ quarantine restrictions in the context of the COVID-19 pandemic;

2. Competitive environment in the housing construction market deteriorated under the influence of the following factors:

- $\quad$ unavailability of project financing mechanisms for small-scale and medium-sized companies;

- $\quad$ exit of small-scale and medium-sized companies from the market in connection with strengthening of regulatory requirements for developers of multi-apartment housing that employ public funds.

3. Demand for new housing in the housing investment market increased due to the following factors:

- inflation expectations;

- devaluation of the national currency;

- decrease in the yield of financial assets;

4. There was an increase in the number of mortgage loans due to the following factors:

- reduction of the key rate of the Bank of Russia and reduction of the cost of credit

resources;

- implementation of the state program of preferential mortgage;

- implementation of regional programs for subsidizing the mortgage rate and initial installment.

5. Prices' growth in the housing market was the result of the previous four trends decreasing supply and simultaneously increasing demand resulted in a certain lack of housing supply in the market and the oligopolized market allowed developers to raise prices of new housing uncontrollably.

The identified negative trends in the development of the housing construction market require some adjustment of the state housing policy in order to prevent the deepening of market imbalances and the development of the economic crisis.

The reported researches were funded by Russian Foundation for Basic Research and by the Tomsk Region Government, grant No 18-410-700013.

\section{References}

1. S. Fischer, Housing and Financial Stability, Amsterdam, Netherlands. (2017). https://www.bis.org/review/r170628c.pdf.

2. L. A. Poliakov, Theory of multiplier and economic mechanism of housing market regulation, Ph.D. thesis, P.G. Demidov Yaroslavl State University, 2000. (in Russian). 
3. Harold M. Katsura, Economic effects of housing investment / Report for USAID Office of Housing and Urban Programs, Washington D.C.

(1984) http://pdf.usaid.gov/pdf_docs/PNAAU426.pdf.

4. T. Y. Ovsiannikova, O. V Rabtsevich, I. V. Yugova, Evaluation of multiplier effect of housing investments in the city economy (AIP Conference Proceedings 3. Youth, Science, Solutions: Ideas and Prospects, YSSIP 2016: Proceedings of the III International Young Researchers Conference "Youth, Science, Solutions: Ideas and Prospects”, 050001, 2017).

5. E. Cerutti, J. Dagher, G. Dell'Ariccia, Housing finance and real-estate booms: A crosscountry perspective (I M F Staff Discussion Note, June 2015, SDN/15/12) URL https://www.imf.org/external/pubs/ft/sdn/2015/sdn1512.pdf

6. Jones Colin. An International Perspective on the Impact of the Global Financial Crisis on Housing Markets (Vestnik of Tomsk state university of architecture and building, No.5, 205-214, 2016) (In Russ.)

7. Commissioning of residential houses in Russia (Rosstat, 2021)

8. Housing and mortgage markets: preliminary results for 2020 (Integrated housing development institution DOM.RF, 2021)

9. Overview of the multi-apartment housing construction market of the Russian Federation as of December 1, 2019: interim results of the transition to project financing using escrow accounts (Integrated housing development institution DOM.RF, 2021)

10. Overview of the multi-apartment housing construction market in the Russian Federation: III quarter of 2020 (Integrated housing development institution DOM.RF, 2021)

11. Research note. Housing construction. - No. 2 (3), October 2020

12. Housing construction and mortgage markets overview: January-June of 2020 (Integrated housing development institution DOM.RF, 2021)

13. Mortgage loans granted to resident individuals and acquired claims thereon: retrospective data up to 01.02.2019 (the Bank of Russia, 2021)

14. Mortgage loans granted to resident individuals and acquired claims thereon (the Bank of Russia, 2021)

15. Average annual prices at primary dwelling markets (Rosstat, 2021)

16. Price indices at primary dwelling markets (Rosstat, 2021)

17. Experts summed up the overall results of 2020 in the market of new buildings. "The Rambler". https://finance.rambler.ru/realty/45597880/?utm_content=finance_media\&utm

18. The Head of Central Bank of Russia E. Nabiullina on the results of the meeting of the Board of Directors on February 12, 2021. https://cbr.ru/press/event/?id=9577

19. Gross Domestic Product Volume Indices in Russia as a percentage to the previous year (Rosstat, 2021) 